\title{
Essential tremor in Rochester, Minnesota: a 45-year study
}

\author{
AH RAJPUT, ${ }^{*}$ KENNETH P OFFORD,$\dagger$ C MARY BEARD,$\dagger$ LT KURLAND $\dagger$ \\ From the Department of Clinical Neurological Sciences, University of Saskatchewan, College of Medicine, \\ Saskatoon, Saskatchewan, Canada, ${ }^{*}$ and the Department of Medical Statistics and Epidemiology, Mayo \\ Clinic, Rochester, Minnesota, USA $\dagger$
}

SUMMARY A 45-year (1935-79) retrospective study of essential tremor based on original medical records on residents of Rochester, Minnesota, is presented. The age and sex adjusted incidence for the most recent 15 year period was 23.7 per 100000 for US white population. The prevalence rate, age and sex adjusted to 1970 US white population on January 1, 1979 was estimated at 305.6 per 100000 . Survival after diagnosis of essential tremor is comparable to age and sex matched population of West North Central United States. Mean age at diagnosis was 58 (range 2-96) years. Age adjusted annual incidence rate was not different in males (18.3/100 000) and females $(17 \cdot 1 / 100000)$. Functional handicap was reported by four $(1 \cdot 5 \%)$ of the 266 incidence cases in school, $13(5 \%)$ cases at work and five cases $(2 \%)$ retired prematurely. Excessive use of alcohol was noted in $16 \%$ and $6 \%$ were diagnosed as alcoholic. Torticollis was diagnosed in $3 \%$ cases and an additional diagnosis of Parkinson's disease after the index date was made in $2 \%$ of incidence cases. Subsequent emergence of Parkinsonism was regarded as incidental. Diagnosis of hypertension was made at some time in $30 \%$ of incidence cases during the period (mean 37 years) for which the medical records were available. Risk of hypertension after onset of essential tremor in the cases was not different from that in a control group.

Tremor is the most prevalent involuntary movement disorder ${ }^{1}$ and essential tremor is one of the most common varieties seen in neurological practice. Essential tremor primarily involves upper limbs and/or head, and unlike the resting tremor of Parkinson's disease, it is evident during action and positioning the limbs. It is inherited as an autosomal dominant trait but the expression is variable. ${ }^{2}$ There has been clinical interest in this disorder for more than a hundred years, ${ }^{3}$ but research activity increased substantially after the report of successful tremor control on propranolol. ${ }^{4}$ We present a descriptive study of essential tremor conducted on the population of Rochester, Minnesota. In the past

Address for reprint requests: Dr AH Rajput, University Hospital, Saskatoon, Saskatchewan, S7N 0X0, Canada.

This work was supported in part by Grant AM30582 and NS17750 from the National Institute of Health Public Service, Bethesda, Maryland.

Received 27 September 1983. Accepted 18 November 1983 this population has proved to be a dependable source of neuro-epidemiological data base for many conditions. ${ }^{5}$ All formal medical diagnoses for residents of Rochester made by a Mayo Clinic physician at the clinic or at Mayo-affiliated hospitals, the physicians at Olmsted Medical Surgical Group, the Rochester State Hospital, the University of Minnesota or Veterans Hospital in Minneapolis, and hospitals anywhere in and around Olmsted County, are entered in the central computerised registry at the Mayo Clinic. Patients with various diagnostic entities can be readily identified and their original comprehensive medical records reviewed, simplifying the longitudinal follow-up for any given illness. ${ }^{5}$

Located in Olmsted County of southern Minnesota, Rochester has a population of approximately 61000 which is primarily of Northern and Western European descent. The local economy is based on farming, health care and light industry. The Mayo Clinic, with more than 720 physicians at present, is the largest multidisciplinary group practice in the United States, ${ }^{5}$ and has provided the primary care for most of the population of Roches- 
ter and surrounding areas since the early 1900 's. There are 42 qualified neurologists at the clinic, many of whom are involved in active training and research programmes.

\section{Methods}

Medical records on all patients diagnosed as having tremor over a 45-year period (1935-79) were reviewed by one of us (AHR). Those patients with an established diagnosis of essential tremor made by a neurologist with or without further qualification (senile, juvenile, hereditary, familial, etc.) were included in the study. Also included were those patients whose diagnosis had been made by a nonneurologist if an adequate description of postural and/or action tremor was noted so that the reviewer was satisfied that the tremor was not a manifestation of cerebellar dysfunction, Parkinson's disease or other systemic problem. Handwriting samples, available in most cases, were used to strengthen the clinical diagnosis as was a positive family history. Those patients who had unilateral, postural and/or action tremor noted once in the medical record but who did not have contralateral involvement over the subsequent five years were excluded from the study.

Medical records on the patients were abstracted for mean of 27.4 years before and 9.7 years after the diagnosis of essential tremor. For the purpose of brevity the date on which essential tremor was diagnosed in each case will be referred to as the index date. The following information was abstracted from the medical records-date of birth, sex, occupation, ethnic background, place of birth, family history of tremor, date of diagnosis of essential tremor, presence of focal or generalised dystonia, psychiatric disorders, history of functional handicap, history of alcohol consumption, history of hypertension, emergence of other neurological features, for example, Parkinsonism after the index date and the date and cause of death, where appropriate. A diagnosis of chronic illness was abstracted only when it had been made on at least two separate occasions. The frequency of hypertension was recorded in the incidence cases $(N=266)$ for the entire period (mean 37 years) the medical records were available. Of interest was development of hypertension subsequent to the index date. For each of the 234 cases that were 45 years or older at the time of last evaluation an index age and sex-matched control from Rochester citizens was identified. In the matched pairs, if either one had hypertension on or before the index date, the pair was excluded from further consideration. In the remaining 155 pairs risk of developing hypertension after the index date was assessed. Statistical analysis included the standard chi-square test for association in a two way contingency table, two sample $t$ test and log-rank test. ${ }^{6}$ Two-tail $p$ values with conventional cut-off value of 0.05 were used throughout.

\section{Results}

During 45 years (1935-79) essential tremor was diagnosed in 266 residents of Rochester and an additional 18 cases moved to the city after diagnosis. Among the 266 incidence cases were 153 females and 113 males. The mean age at diagnosis was 58 (range 2-96) years for the incidence cases. Although date of diagnosis was easy to obtain from the medical records, the date of onset of tremor could not be satisfactorily established in most cases.

Age and sex specific annual incidence rates over the 45 year period are shown in table 1 . The age specific incidence rises sharply after age 49 and reaches the peak $(84 \cdot 3 / 100000$ annual) in those 80 and above. The 45 year period was divided into three 15 year intervals. The age specific incidence during each 15 year interval are illustrated in table 2. The incidence of cases diagnosed after age 39

Table 1 Age and sex specific annual incidence rates per (100 000) in Rochester, Minnesota (1935-79)

\begin{tabular}{|c|c|c|c|c|c|c|}
\hline $\begin{array}{l}\text { Age Range } \\
\text { (yrs) }\end{array}$ & $\begin{array}{l}\text { Females } \\
\text { Number }\end{array}$ & Incidence & $\begin{array}{l}\text { Males } \\
\text { Number }\end{array}$ & Incidence & $\begin{array}{l}\text { Total } \\
\text { Number }\end{array}$ & Incidence \\
\hline $\begin{array}{l}0-19 \\
20-39 \\
40-49 \\
50-59 \\
60-69 \\
70-79 \\
80+ \\
\text { Total (unadjusted) }\end{array}$ & $\begin{array}{r}6 \\
19 \\
15 \\
22 \\
41 \\
35 \\
15 \\
153\end{array}$ & $\begin{array}{r}1 \cdot 9 \\
6 \cdot 2 \\
14 \cdot 9 \\
25 \cdot 7 \\
61 \cdot 7 \\
80 \cdot 7 \\
74 \cdot 0 \\
16 \cdot 2\end{array}$ & $\begin{array}{r}8 \\
10 \\
11 \\
31 \\
25 \\
18 \\
10 \\
113\end{array}$ & $\begin{array}{r}2 \cdot 7 \\
4 \cdot 4 \\
12 \cdot 6 \\
46 \cdot 1 \\
54 \cdot 1 \\
69 \cdot 7 \\
106 \cdot 6 \\
14 \cdot 8\end{array}$ & $\begin{array}{r}14 \\
29 \\
26 \\
53 \\
66 \\
53 \\
25 \\
266\end{array}$ & $\begin{array}{r}2 \cdot 3 \\
5 \cdot 4 \\
13 \cdot 9 \\
34 \cdot 6 \\
58 \cdot 6 \\
76 \cdot 6 \\
84 \cdot 3 \\
15 \cdot 6\end{array}$ \\
\hline
\end{tabular}

Table 2 Essential tremor age specific rate per (100 000) in males and females combined in Rochester, Minnesota

\begin{tabular}{lccc}
\hline Years Age & $1935-49$ & $1950-64$ & $1965-79$ \\
\hline $0-19$ & $0 \cdot 0$ & $2 \cdot 5$ & $2 \cdot 9$ \\
$20-39$ & $2 \cdot 9$ & $6 \cdot 3$ & $6 \cdot 3$ \\
$40-49$ & $12 \cdot 3$ & $8 \cdot 3$ & $19 \cdot 2$ \\
$50-59$ & $16 \cdot 7$ & $31 \cdot 5$ & $46 \cdot 8$ \\
$60-69$ & $17 \cdot 2$ & $65 \cdot 1$ & $72 \cdot 6$ \\
$70-79$ & $8 \cdot 2$ & $68 \cdot 0$ & $105 \cdot 8$ \\
$80+$ & $0 \cdot 0$ & $24 \cdot 2$ & $135 \cdot 7$ \\
\hline
\end{tabular}


Table 3 Annual incidence of essential tremor in Rochester, Minnesota per 100000 population (adjusted to 1970 US white population)

\begin{tabular}{|c|c|c|c|c|}
\hline $\begin{array}{l}\text { Calendar } \\
\text { period }\end{array}$ & $\begin{array}{l}\text { Age adjusted } \\
\text { For females }\end{array}$ & $\begin{array}{l}\text { Age adjusted } \\
\text { for males }\end{array}$ & $\begin{array}{l}\text { Total age } \\
\text { adjusted }\end{array}$ & $\begin{array}{l}\text { Total age and } \\
\text { sex adjusted }\end{array}$ \\
\hline $\begin{array}{l}1935-49 \\
1950-64 \\
1965-79 \\
1935-1979 \text { Total }\end{array}$ & $\begin{array}{r}6 \cdot 0 \\
15 \cdot 2 \\
22 \cdot 6 \\
17 \cdot 1\end{array}$ & $\begin{array}{r}5 \cdot 4 \\
16 \cdot 8 \\
25 \cdot 0 \\
18 \cdot 3\end{array}$ & $\begin{array}{r}5 \cdot 8 \\
15 \cdot 8 \\
23 \cdot 5 \\
17 \cdot 6\end{array}$ & $\begin{array}{r}5 \cdot 8 \\
15 \cdot 9 \\
23 \cdot 7 \\
17 \cdot 6\end{array}$ \\
\hline
\end{tabular}

years increased substantially during the last (196579) interval. There was a remarkable rise in cases diagnosed after age 49 years in the post-World War II period. Table 3 shows annual incidence rates per 100000 age and sex adjusted to 1970 US white population. There is no difference in age adjusted incidence rates between males (18.3) and females $(17 \cdot 1)$. The estimated prevalence rate on January 1 , 1979 adjusted for age and sex to the 1970 US white population was 305.6 per 100000 . Aside from the fact that most females were housewives, there was no association between essential tremor and occupation. A family history of tremor was reported in 103 (39\%) of the incidence cases.

The mean length of medical records was 27.4 years before and 9.7 years following the diagnosis of essential tremor. At the last follow-up, 85 of the 266 incidence cases were deceased, with the most common cause of death being bronchopneumonia (13) and complications of malignancy (11) cases. Life expectancy in essential tremor cases is very similar

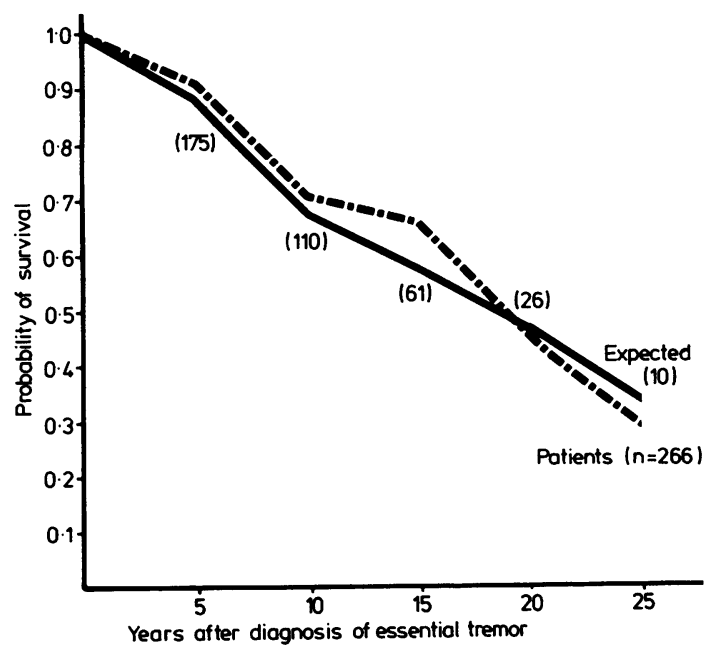

Fig Survival following diagnosis of essential tremor in 266 incidence cases compared to the expected survival for persons of like age and sex and calendar year of birth from the West North Central region of US. In parentheses are number of essential tremor cases at 5 year intervals following diagnosis. to that of the general population of the West North Central region of the USA for persons of like age and sex (fig). In only a small percentage of cases handicap due to tremor occurred during school years $(1.5 \%)$ or at the job $(5 \%)$. Two patients changed jobs because of the tremor, while five $(2 \%)$ others retired prematurely.

Psychoneurosis was diagnosed in $16 \%$ cases prior to the index date. Excessive use of alcohol was reported in $42(16 \%)$ cases. Among these were 16 cases diagnosed as alcoholic - six before, three at, and seven following the index date. Torticollis was diagnosed in seven $(2.6 \%)$ cases-four before, two concurrent, and one following the index date. Ataxia was noted in six (2\%) cases-one before, three at, and two after the index date. Parkinson's disease was suspected in eight cases before the index date but the diagnosis was later rescinded. Additional diagnosis of Parkinsonism was made in six (2\%) cases after the index date. Hypertension was diagnosed in $80(30 \%)$ cases -46 before, eight at, and 26 after the index date. In the 155 pairs where neither the case nor control had hypertension as of index date, subsequent development of hypertension was estimated using actuarial survival techniques and the log-rank test. ${ }^{6}$ The log-rank test did not detect a difference in the risk of developing hypertension between the two groups $(p>0 \cdot 10)$.

\section{Discussion}

The first epidemiological study on essential tremor was that reported by Larsson and Sjogren in $1960^{7}$ in an isolated Northern Sweden community. These workers had deliberately chosen this area of high prevalence to ensure cooperation of the population. They reported a prevalence rate of $1700 / 100000$. This study has been criticised for using diagnostic criteria that are at variance with the accepted definition of essential tremor and all patients were not examined by a qualified physician. ${ }^{8}$ The high prevalence rate probably reflects a long history of perpetuation of essential tremor gene in this relatively isolated community which was known for high frequency of intermarriage and consanguinity. Hornabrook and Nagurney' studied essential tremor in different regions of Papua, New Guinea. Essential 
tremor was known to occur quite frequently in some regions and was thus well known to the general population. Such awareness was so common in some areas that $96 \%$ of the cases were identified during census patrols. They noted wide regional differences in prevalence of essential tremor with no cases in some and 21000 cases per 100000 population in other areas.

There are two recent reports ${ }^{11}$ on the prevalence of essential tremor in populations that were not known for a high frequency of this disorder. These two studies are of the same basic design-the population was surveyed with a questionnaire to identify possible cases following which those suspected of essential tremor were examined by a neurologist. The diagnostic criteria were however different, one group included only those patients that had hand function or speech impairment due to tremor ${ }^{11}$ while the other study utilised less stringent requirements. ${ }^{10}$ Haerer et $a^{11}$ estimated prevalence rate of 414.6 while Rautakorpi ${ }^{10}$ noted $5500 / 100000$ population. These differences are so vast that differences in diagnostic criteria alone would not be a satisfactory explanation. While Rautakorpi et $\mathbf{l}^{10}$ studied a relatively homogeneous Finnish population, Haerer et $a l^{\prime \prime}$ evaluated a population consisting of mixed European descent and of African ancestry. Both these studies utilised mass survey and included only those persons who were $\mathbf{4 0}$ years or older. In contrast we surveyed the medical records and included all Rochester residents regardless of age. These differences in methodology may account for lower prevalence rate $(305.6 / 100000)$ in our study when compared to that reported by Haerer et al ${ }^{11}(414 \cdot 6 /$ $100000)$.

Essential tremor has been reported to be more common in males by some workers ${ }^{70}$ and in females by others. " "We found no difference in age adjusted incidence rates in males $(18 \cdot 3)$ and females $(17 \cdot 1)$. When the three 15 year intervals of our study are considered there has been a progressive increase in incidence rate (table 3 ). We attribute this rise to greater physician awareness of essential tremor and availability of better medical care for the older population after World War II and consequent to Medicare in the US. The annual incidence rate of $23.7 / 100000$ for the most recent 15 year period we believe is representative for today. There are no incidence studies on essential tremor in English literature but the incidence in the United Kingdom is believed to be similar to that of Parkinson's disease. ${ }^{12}$ Our data indicate that indeed this may be the case for Rochester as well, since the annual incidence of Parkinsonism for the same period is 20.5/ $100000 .{ }^{13}$ Since the mortality rate for Parkinsonism is higher while for essential tremor it is similar to general population (fig). The prevalence rate for essential tremor at any given point would therefore be higher than that of Parkinson's disease. Like other reports ${ }^{10} 11$ we found an increase in incidence with advancing age.

In the past essential tremor was regarded as a monosymptomatic disorder, ${ }^{814}$ is but more recent studies provide some contrary evidence. A strong association between essential tremor and focal or regional dystonia has been reported by several workers. ${ }^{16-20}$ Torticollis was noted in $7 \%$ cases in one study ${ }^{17}$ while in the present report only $3 \%$ had torticollis noted in the medical records at any time. It is possible that mild torticollis cases in our patients were not commented upon.

The relationship between essential tremor and Parkinsonism is not fully established and the inability to distinguish the two disorders is not uncommon. ${ }^{21}$ At a late stage of essential tremor, resting tremor (which is typical of Parkinsonism) may be present in these cases. ${ }^{21}{ }^{22}$ When the distinction between essential tremor and Parkinsonism is not possible on clinical valuation, no other investigations may help differentiate these two conditions. ${ }^{23-25} \mathrm{~A}$ strong association between essential tremor and Parkinson's disease was reported by Hornabrook and Nagurney. ${ }^{9}$ They noted that the risk of developing Parkinson's disease was $\mathbf{3 5}$ times higher in those patients who had essential tremor as contrasted to those who did not. Barbeau and Pourcher ${ }^{26}$ have reported a strong family history of essential tremor in those Parkinsonian patients whose disease began at a relatively young age. In our series only six $(2 \%)$ of the 266 incidence cases had an additional diagnosis of Parkinson's disease subsequent to the index date. Parkinson's disease is a common condition with $2.5 \%$ cumulative lifetime risk and prevalence rate of $1 \%$ over age 60 years. ${ }^{27}$ The concurrent diagnosis of essential tremor and Parkinson's disease in our series we believe is incidental.

Systematic hypertension was noted in $31 \%$ of essential tremor cases in one preliminary report from a referral centre. ${ }^{28}$ We attempted to verify that observation. Hypertension was diagnosed in $30 \%$ of the incidence cases at some time during the course of follow-up (mean 37 years). Because similar information is not available in comparable population, it is not possible to establish whether the lifetime risk of hypertension in essential tremor cases is different from expected. In those cases who at last evaluation were 45 years or older we identified age and sex matched controls. Among the 234 so matched pairs were 155 in whom neither the patient nor his or her control had hypertension up to and including the index date. These 155 pairs were then analysed in a retrograde fashion to determine 
the frequency of hypertension occurring after the index date. There was no significant difference $(p>$ $0 \cdot 10$ ) between cases and controls for risk of hypertension subsequent to the diagnosis of essential tremor. We recognise this is less than an ideal method of definitely answering the question.

The effectiveness of alcohol in symptomatic control of tremor is well recognised in some cases. ${ }^{23}$ Those who benefit from alcohol with time would often require larger quantities to obtain relief. Larsson and Sjogren' noted no case of alcoholism among the essential tremor patients. Schroeder and Nasrullah, ${ }^{29}$ on the other hand, noted that the frequency of excessive alcohol intake and alcohol dependence in essential tremor patients was more than double that in the control population. In our patients, $16 \%$ abused alcohol and $6 \%$ were diagnosed as alcoholic, yet $39 \%$ of the essential tremor patients had never used alcohol.

It has been generally accepted that essential tremor does not lead to functional handicap or shortened life expectancy. Hence the term benign essential tremor is frequently used. Functional handicap in these patients may be the direct result of tremor or due to psychological factors. ${ }^{918}{ }^{10}$ In the present study only a small number of cases reported problems at school or job. Since this study was based on a review of medical records and was not designed as a patient survey to evaluate disability it is presumed that only those cases who had significant problems reported them to the physician. Although essential tremor could produce functional handicap in some cases and as such is not benign the life expectancy in these cases is comparable to that of the general population and from that point of view it could genuinely be classified as a benign disorder.

\section{References}

' Jankovic J, Fahn S. Physiologic and pathologic tremors. Ann Int Med 1980;93:460-5.

${ }^{2}$ Marshall J. Tremor. In: Vinken PJ, Bruyn GW, eds. Handbook of Clinical Neurology Diseases of basal ganglia. Amsterdam: North-Holland Publishing, Vol. 6, 1968, pp. 809-25.

${ }^{3}$ Murray TJ. Treatment of essential tremor by propranolol. Can Med Assoc J 1972;107:984-6.

4 Winkler GF, Young RR. The control of essential tremor by propranolol. Trans Am Neurol Assoc 1971;96, reprinted by ANA, 1972.

${ }^{5}$ Kurland LT, Molgaard CA. The patient record in epidemiology. Sci Am 1981;4;245:54-63.

- Mantel N. Ranking procedures for arbitrarily restricted observations. Biometrics 1967;23:65-78.

${ }^{7}$ Larsson T, Sjogren T. Essential tremor: A clinical and genetic population study. Act Psych Neurol Scand 1960;36:(Suppl. 144):1-176.

${ }^{8}$ Ashenhurst EM. The nature of essential tremor. CMA J
1973;109:876-78.

${ }^{9}$ Hornabrook RW, Nagurney JT. Essential tremor in Papua New Guinea. Brain 1976;99:659-72.

${ }^{10}$ Rautakorpi I, Takala RJ, Marttila K, Sievers, Rinne UK. Essential tremor in a Finnish population. Acta Neurol Scand 1982;66:58-67.

"Haerer AF, Anderson DW, Schoenberg BS. Prevalence of essential tremor. Results from Copiah County study. Arch Neurol 1982;39:750-51.

${ }^{12}$ Sevitt I. A comparison of propranolol and benzhexol in essential tremor. Practitioner 1974;213:91-96.

${ }^{13}$ Rajput AH, Elveback LR, Beard CM, Kurland LT. Epidemiology of Parkinson's disease in Rochester, Minnesota. Trans Amer 12th World Congress of Neurology, Kyoto, Japan, 1981. Ann Neurol (in press)

14 Davis CH, Kunkle EC. Benign essential (heredofamilial) tremor. Arch Intern Med 1951;87:808-16.

is Magee KR. Essential tremor: diagnosis and treatment. Clin Med 1965;72:33-41.

${ }^{16}$ Couch JR. Dystonia and tremor in spasmodic torticollis. In: Eldridge R, Fahn S, eds. Advances in Neurology. New York: Raven Press, 1976. Vol. 14: pp. 245-258.

${ }^{17}$ Baxter DW, Lal S. Essential tremor and dystonic syndromes. In: Poirier LJ, Sourkes TL, Bedard PJ, eds. Advances in Neurology. New York: Raven Press, 1979. Vol. 24: pp. 373-377.

${ }^{18}$ Rajput AH. Essential tremor that is not "benign". Trans Can Congress of Neurology Sci 1976.

${ }^{19}$ Aminoff MJ, Dedo HH, Izdebski K. Clinical aspects of spasmodic dysphonia. J Neurol Neurosurg Psychiatry 1978;41:361-5.

${ }^{20}$ Jenkovic J, Ford J. Blephrospasm and orofacial-cervical dystonia: clinical and pharmacological findings in 100 patients. Ann Neurol 1983;13:402-11.

${ }^{21}$ Murray TJ. Essential tremor. Can Med Assoc J 1981; 124:1559-65.

${ }^{22}$ Murray TJ. Long-term therapy of essential tremor with propanolol. CMA J 1976;115:892-4.

${ }^{23}$ Rajput AH, Jamieson H, Hirsh S, Quraishi A. Relative efficacy of alcohol and propranolol in action tremor. Can J Neurol Sci 1975;2:31-5.

${ }^{24}$ Shahani BT, Young RR. Physiological and pharmacological aids in the differential diagnosis of tremor. $J$ Neurol Neurosurg Psychiatry 1976;39:772-83.

${ }^{25}$ Findley LJ, Gresty MA, Halmagyi GM. Tremor, the cogwheel phenomenon and clonus in Parkinson's disease. J Neurol Neurosurg Psychiatry 1981;44,6: 534-46.

${ }^{26}$ Barbeau A, Pourcher E. New data on the genetics of Parkinson's disease. Can J Neurol Sci 1982;9:53-60.

${ }^{27}$ Kurland LT. Epidemiology: incidence, geographic distribution, and genetic considerations. In: Field W, ed. Pathogenesis and Treatment of Parkinsonism. Springfield, Illinois: Charles C. Thomas, Publisher. 1958; pp. 5-43.

${ }^{28}$ Rajput AH, Wilson TW, MacFadyen DJ, Rozdilsky B. Essential hypertension (HT) and essential tremor (ET). Trans Can Congress Neurol Sci 1978.

${ }^{29}$ Schroeder D, Nasrallah HA. High alcoholism rate in patients with essential tremor. Am J Psychiatry 1982;139:1471-3.

${ }^{30}$ Critchley E. Clinical manifestations of essential tremor. $J$ Neurol Neurosurg Psychiatry 1972;35:365-72. 